\title{
Common Sense in the Laboratory
}

\author{
Some of the Ways in Which Better Executive Control Might Aid Electrical Research \\ By Professor Vladimir Karapetoff, Cornell University
}

THE most natural division of unsolved problems 1 would be according to the types of ipparatus: for example, into problems in the design and operation of large turbo-alternators, improvements in lamps, circuit-breakers for larger currents and higher voltages, etc. Such problems may be multiplied ad infinitum, and I should not venture to express my personal opinion upon their relative importance. Hundreds of opinions have been expressed by competent men as to the specific needs for theoretical or experimental research in practically every branch of the electrical industry. I wish to offer another and somewhat unusual classification for the pending research problems which may be more helpful to those interested only in the broader aspects of research.

\section{Where Caliber of Investigator Counts}

One division of research problems that seems to me to he quite essential is based upon the caliber and mental equipment of the investigator himself. There are problems of great practical importance which can and will be solved by the expenditure of a sufficient amount of money and time. Thus, during the war the shortage of certain materials led to a large number of tests on substitutes, and in some cases satisfactory materials were found by men of average ability and education. A large number of such tests, sometimes dignified by the name of research, is being carried on all the time. For example, there are certain varieties of mica on the market or lubricating oils offered by the principal concerns, and comparatively simple tests permit to determine the kind best suited for a given purpose without employing men of unusually high caliber.

At the other end of the scale we have researches which require men of exceptional intellectual power and of wide erudition, researches which have baffled the most persistent efforts of many years and problems which remain unanswered in spite of the most alluring financial inigh-tension insulator and a simple variable-speed alternating-current motor may be mentioned as two such examples. Between these extremes there are innumerable gradation of mental caliber required for the solution of different kinds of research problems, and a clear realization of this fact is of utmost importance in the cultural development of the country. The tendency is to lay too much stress on material resources, equipment, and, other external factors. A few men of superior caliber and thoroughly trained will accomplish results on which thousands of less gifted and not so thoroughly trained investigators may work for many years without much progress.

The necessity for better conservation of persons of exceptional scientific intellect is so urgent that it is legitimate to ask ourselves what our government, leaders of industry, educational institutions, or any other agencies are doing in this direction. The answer is, next to nothing. Moreover, in this imperfect world of ours it is no one's particular business to attend to the proper development of geniuses.

I do not have in mind a somewhat utopian scheme of breeding a race of intellectual giants by careful mating. I have in mind a perfectly feasible scheme of detecting exceptional children by suitable mental tests and then guiding them year after year to the full development of their mental powers. This is a proper function of the state and some day will become a reality.

\section{Pure and Applied Research}

Another classification of research problems is in accordance with their proximity to or remoteness from the direct industrial applications. A certain physical phenomenon, a mathematical formula, a peculiar alloy, etc., may up to a certain time possess no practical importance and be merely a subject of personal interest to a few investigators. Then one day someone discovers that that particular alloy or formula offers great practical possibilities and it becomes the subject of extensive industrial researches.

While such a state of affairs may seem perfectly natural and unavoidable, it has certain serious drawbacks for the best development of the art. The elec- trical industry owes many of its triumphs to so-called pure physical research, but until recently this industry offered mighty little encouragement to such research or to its exponents. Had the leaders of the electrical industry realized earlier the tremendous possibilities of physical research in improving commercial apparatus, then instead of sneering at "doctors" they would have used their talent long ago, and we would have been much further advanced in the applications of electricity than we are now.

But, it may be retorted, the scope of physics is infinite and how can an industrial concern keep on sinking hundreds of thousands of dollars year after year on the mere possibility that some of the results of physical research may at some time prove to be of use to it? The real situation is this: physical, chemical, or mathematical research involves first of all a method of approach, a method of attack upon is iertain group of related problems, based on a thorough familiarity with the resources of that particular science. Promotion of research, therefore, consists primarily in the encouragement of the study and further development of such methods and not in the acquisition of a large number of unrelated facts. A scientist trained, say, in alternating currents will be prepared to approach a new problem in this field with much better chance of success than one who has had merely general practical experience and beats about the bush in an effort to discover a short cut by luck.

Thus the promotion of pure research is another national problem and the first aim must be the training

his effort, imagination, and inspiration where it will bear the best fruit and it will enable two or more investigators to combine their efforts without jealousy or duplication.

Almost any big research problem involves some theoretical study as well as experimental skill, inventive ability, and patient search for the work of other investigators and its critical analysis. Only a very few investigators possess all these accomplishments to tile same degree, and it is in the hands of a harmoniously organized group of scientific workers of different talents that research leads to gratifying results.

A chain is strong only as its weakest link. Many a research worker has struggled in vain with a problem for which he was eminently fitted, just because he failed to recognize this one weak link in himself or was too proud to ask for help on some point of difficulty.

The Anglo-Saxon race is individualistically inclinecl perhaps to a greater degree than the other civilized races. The Americans among the Anglo-Saxons are especially prone to exhibit the western pioneer spirit in research with all its virtues and shortcomings of which the utter disregard of the work of preceding investigators is perhaps the most characteristic one.

\section{Team Work in Research}

I do not mean to imply for an instant that an original thinker should be hampered in the flight of his fancy by laboratory assistants or by skilled mediocrities, in the name of a misapplied principle of coöperation. I mean two other things. First, to clear a big idea in his mind, he ought to know how to let go of it and allow his assistants to play with it for a while and see how it shapes itself in detail. Secondly, if in the preliminary molding of his ideas he should be handicapped by his lack of mathematical ability or of foreign languages (two handicaps common in this country) let him not try to solve the problem in an imperfect manner alone without first having exhausted the possibilities of associating with other gifted and congenial minds who may furnish the missing needs of the problem.

An outsider and often a manager thinks that research men specialize by subject, so that one knows all about direct-current machines, another all about transformers, etc. While to some extent this is true yet there is a much more thorough-going and desirable specialization according to the nature of the man's talent. One is es-

in the methods of analysis, general laboratory methods, the ability to find what is already known, the use of mathematics, the use of methods borrowed from other branches of science, general accuracy of measurements, of computations, of statements, and last, though not least, that loving atitude toward nature and the intuition that comes only from a first-hand contact intuition that comes only from a first-hand contact any preconceived theory or utilitarian thought.

In the early development of our industry we sneered at all research. Then we called plain testing research. Later we grudgingly tolerated industrial research, that is, an investigation of a particular piece of apparatus in its complexity. Finally, it began to dawn upon some of us that an investigation of the very physical elements which enter into that particular piece of apparatus may lead to interesting discoveries. In this way it gradually became clear that a thorough investigation of the physical laws governing this or that branch of industry may be the quickest and the surest way toward remedying the difficulties in the operation and construction of certain pieces of apparatus. I should not be surprised if in a few years we should make a fad of pure research in industrial establishments and overdo it as we overdid safety and efficiency and patriotism and many other good things.

\section{Experimental and Theoretical Research}

The next division of research problems is into experimental, mathematical, inventive, critical, indicative of new fields, etc. A clear understanding of this division on the part of investigators themselves and of their business managers will help scientific progress materially in that it will allow each one to apply pecially gifted in arranging ingenious methods for accurately measuring difficult quantities, whether it be in a-c or d-c machinery, another can skilfully present a phenomenon or a relationship in a mathematical form, a third is particularly adept in finding out quickly and accurately all the preceding contributions on the subject and in assigning the proper relative value or subject and in assigning

The possibilities of coöperation in research on the part of persons of different temperament and ability go far beyond the confines of one industrial organization or even one country. International coöperation in research is just as important in view of the favorable and unfavorable racial idiosyncrasies.

A student of the history of science can easily recall cases in which a scientific idea is born in one country and then is taken up by someone in another country and finally brought to a fruitful development in a third country. Perhaps the best known example in our line is that of Hertz, a German, who acted as an intermediary between Maxwell, an Englishman and Marconi, an Italian. A biologist could easily get examples of living organisms which have to live under different conditions at the various stages of their development. Thus the rust of wheat must live un barberry before it can live on wheat. We in this country with its polyglot population have had an exceptional opportunity to observe and to benefit by this coöperation right in our midst, even though in our Anglo-Saxon arrogance we are apt to look down upon our brothers from across the seas. There is hardly an organized institution for research in this country that cannot point to benefits derived from associates that cannot point to benefits derived from asso
of foreign birth and training and point of view. 